\title{
Relationship between Healthcare Provider's Perception about Patient Safety and Patient Safety Implementation in The Emergency Department
}

\author{
Yayan Mulyana ${ }^{1}$, Yanny Trisyani ${ }^{2}$, Etika Emaliyawati ${ }^{3}$ \\ ${ }^{1}$ Gunung Jati Hospital, Cirebon, Indonesia \\ ${ }^{2,3}$ Faculty of Nursing Universitas Padjadjaran, Bandung, Indonesia \\ Corresponding email: yayanmulyana17474@gmail.com
}

Submitted: 28-08-2018 Accepted: 16-04-2020 Published: 22-04-2020

\begin{abstract}
The Emergency Department (ED) is a hospital service unit that provides the first service for patients with disease conditions that threaten their lives or can cause disability for 24 hours. Implementation of patient safety in theED should be applied to minimize the risk of error handling for the patient. ED staff perceptions related to the implementation of patient safety is a factor that directly-related to his behavior in applying the implementation of patient safety. This study aimed to analyze the relationship between perceptions of staff ED and patient safety by implementing patient safety at the Regional Hospital Emergency Department Cirebon. This study was a correlational study with the crosssectional approach of 99 emergency staff with total sampling at Cirebon. Collecting data used questionnaires of patient safety. Based on the results of the univariate analysis showed that the majority $(80 \%)$ of respondents either category on the implementation of the sub-variables of patient safety team collaboration and communication, only a small proportion of respondents less category $(20 \%)$ on the implementation of the sub-variables of patient safety team collaboration and communication. In addition, less than half $(49.5 \%)$ category lacking in implementing patient safety, only half $(50.5 \%)$ categories, both in the implementation of patient safety. Based on the results of the bivariate analysis showed that the relationship implementation of patient safety with all the variables, namely teamwork $(p$-value $=0.000)$, communications $(p$-value $=0.005)$, the concept of patient safety $(p$-value $=0.005)$, and perception ( $\mathrm{p}$-value $=0.005)$. Based on the results of the study, the researchers concluded that the relationship between staff perceptions of the emergency department (ED) on patient safety by implementing patient safety at the Regional Hospital emergency department (RSD) Cirebon. IGD support staff perceptions of patient safety, but still found lacking in the category of health workers implementation of patient safety, so the need for patient safety education and training with simulation methods to illustrate the approach in the implementation of patient safety.
\end{abstract}

Keywords: Emergency staff, perception, the implementation of patient safety. 
Yayan Mulyana: Relationship between Healthcare Provider's Perception about Patient Safety and Patient Safety

\section{Introduction}

The Emergency Department (ED) is a hospital service providing services during the first 24 hours in patients with the threat of death and disability, Services provided interdisciplinary involving all health professions include doctors, nurses, energy analysts, and pharmacy staff. The medical profession in their service delivery to address the interdependence of health in order to improve health care for patients (Ministry of Health, 2011). Type of patients who need examination and immediate action especially in critical condition, both in acute cases of non-trauma, acute cases of trauma, patients with psychiatric disorders, patients with infectious diseases, and the patients were exposed to chemical or biological (Australian College for Emergency Medicine, 2014).

Pratama health services that have ED facilities and referral health services should have facilities and infrastructure that are equipped with emergency equipment. In addition, all ED staff should have sufficient competence and capability for handling emergency cases. Handling victims who are not immediately carried out can cause various problems such as increased risk of disability, complications and even the risk of death (Emaliyawati, Prawesti, Yosep, \& Ibrahim, 2016). Patients are in an emergency condition and must be given immediate action at least will cause anxiety for both the patient or the health care staff themselves, especially nurses who handle (Shari, Suryani, \& Emaliyawati, 2014).

Service to the emergency conditions often faced with an increasing number of patients and severity levels. Patients seeking treatment for primary and urgent complaints, any time day or night, so that frequent emergency conditions met by patients with various conditions and levels of severity. It is certainly need high skills of health personnel in the decision to prioritize services according to the level of severity. Conditions incoming emergency patients with a number of unexpected and different severity became one of the factors that make health workers are overwhelmed in dealing with patients. Therefore, it will be an imbalance that can have an impact on safety patient threat
(Brenna, 2016).

Sherman et al. (2009) states that human and organizational factors are factors that contribute to patient safety, it affects the behavior of health staff in relation to safe patient care. Referring to the concept of patient safety, although the program of patient safety has been socialized in clinical areas, but problems in the field has found the tendency of various conditions such as crowding, lack of staff, the waiting time extends, the lack of major appliance, resulting in patient services that are safety becomes less than the maximum (Agency for Healthcare Research and Quality, 2013).

Complex services in the emergency department is closely related to various risk factors for patient safety that could potentially cause injury and harm to patients such as patient handling errors (Runciman et al., 2009). As the results of research Horwitz et al. (2009), about a common problem in the ED tends to lead to the risk of patient safety that include communication failures, lack of teamwork, and crowding. Other studies on patient safety in the emergency room mention that interruptions and multitasking are considered factors contributing to errors (Westbrook, 2014). Based on the description above, shows that the communication failure factors, lack of teamwork, crowding, interruptions, and multitasking is a factor that is very influential on patient safety in the emergency department.

Integral skills in managing multiple tasks at the same time required in the emergency room. According to the results of research Patel and Cohen (2008) that the work of doctors and nurses in the emergency room that is unique clinical environment tends to occurrence of multitasking. Activities most often performed by doctors and nurses while doing multitasking namely the exchange of information (Lena et al., 2012), Although the effect on the creation of a working memory load is higher (Guttmann et al., 2011). Two studies in Denmark is based on questionnaires to doctors and ED nurse's, that multitasking often as stress factors that can interfere with the performance. This has the effect of errors caused by the high cognitive demands on services multitasking (Sorra et al., 2009).

Implementation of patient safety is activity 
intended reducing the possibility of side effects associated with health care (Shojania et al., 2001), The complexity inherent in the emergency services such as employment in the same time, uncertainty, change of plans, and a high workload. Interactive complexity in the emergency services often cause unfavorable attitude among staff in dealing with patients, so that errors often result from the behavior of health care in this unit (Peters $\&$ Peters, 2008). Behavior in health services cover all activities or activities of individuals both observable and unobservable relating to the maintenance and improvement of health influenced the perception of the individual (Sobur, 2011). For creating the perception that support the realization of the health service needs to be supported by the competence of health professional's patient safety (Jeffs et al., 2013). Consistent research Bovbjerg, Miller, and Shapiro (2001), which states that the services provided appropriate professional responsibility and discipline will affect the increase in perception and execution patient safety,

Perception is an individual view of something that will make a response and behave (Walgito, 2002). The theory states that the health belief model of individual plays a role in determining the attitude of doing or not doing health behavior (Conner, 2005). Appropriate research Rosenstoch (1974) in theory health belief model of states that individual behavior is influenced by individual perceptions about the threat of health problems and the corresponding value of actions aimed at reducing the threat. Perceptions of health workers leading to actions that affect patient safety, which is important for the hospital. Health workers are important resources for the hospital or health care provider to ensure patient safety (Aiken et al., 2002; Berney \& Needleman, 2006). Given the important position in the provision of health services, it is necessary to understand the perception of health professionals on patient safety (Affonso et al., 2003). This study aimed to analyze the relationship between staff perceptions of the emergency department (ED) on patient safety by implementing patient safety at the Regional Hospital emergency department (RSD) Cirebon.

\section{Method}

This research is a quantitative research using analytic descriptive study with cross sectional study design. The study was conducted from June to July 2018 at ED (RSD) Cirebon, West Java. The non-probability sampling technique was used with a total of ninety-nine $(n=99)$ participants.

This study used three questionnaires namely demographic questionnaire, a questionnaire of perception, observation and questionnaires related to the implementation of patient safety healthcare provider's in the ED. Demograph questionnaire containing age, sex, length of employment, job position. Researchers used questionnaire adopted from Hospital Survey on Patient Safety Culture developed by The Agency for Healthcare Research and Quality (AHRQ) (2007) and observation using a questionnaire emergency assessment team measure (TEAM) according to the guidelines Cooper et al. (2010). Researchers conducted a back translation and the validity and reliability of the questionnaire on the ED staff of 40 people using the Pearson product moment correlation for validity and KR-20 and Cronbach's alpha reliability. All items on the questionnaire perception and implementation of patient safety are valid. The questionnaire is said to reliability because reliability coefficient greater than 0.7 . Univariate analysis was used to determine the frequency of each variable. Analysis using a bivariate test with Kendal's Tau b test. Before collecting the data has been carried out ethical clearance from Universitas Padjadjaran Research Ethics Committee on May, 2018 No. 472 / UN6.KEP / EC / 2018.

\section{Results}

Research results in Table 1 showed that more than half $(57.58 \%)$ of respondents are male, most aged 26-30 years are at intervals of as many as $46.46 \%$, the highest education level is Diploma (13 nurses, midwives 8 , pharmaceuticals 6 , the analyst 21 ), amounting to $48.48 \%$, the highest working period at intervals of $1-3$ years is $35.35 \%$ of respondents, while the average patient visit pebulan mostly in yellow triage is $69.91 \%$. 
Yayan Mulyana: Relationship between Healthcare Provider's Perception about Patient Safety and Patient Safety

Table 1 Frequency Distribution Characteristics of Respondents and Number of Visits Patients at ED (RSD) Cirebon $(n=99)$

\begin{tabular}{llcc}
\hline Variables & Category & F & $\mathbf{\%}$ \\
\hline Age & $18-25$ yr & 12 & 12.12 \\
& $26-30$ yr & 46 & 46.46 \\
Gender & $31-40$ yr & 25 & 25.25 \\
Years of Service & $41-50$ yr & 16 & 16.16 \\
& Man & 57 & 57.58 \\
& Woman & 42 & 42.42 \\
Profession & 6 mon-1 yr & 2 & 2.02 \\
& $1-3$ yr & 35 & 35.35 \\
& $3-5$ yr & 27 & 27.27 \\
Education & $5-10$ yr & 16 & 16.16 \\
& $>10$ yr & 19 & 26.26 \\
& Doctor & 26 & 26.26 \\
& Nurse & 32 & 32.32 \\
Averioge number from January to June 2018 & Midwife & 11 & 11.11 \\
& Pharmacy Personnel & 9 & 9.09 \\
& Power Analyst & 21 & 21.21 \\
& D3 & 48 & 48.48 \\
& D4 & 8 & 8.08 \\
& S1 Nurses & 15 & 15.15 \\
& S1 Doctor & 26 & 26.26 \\
& S1 Pharmacists & 1 & 1.01 \\
& Masters in Nursing & 1 & 1.01 \\
& Triage & & \\
& Red & 335 & 11.88 \\
& Yellow & 1970 & 69.91 \\
& Green & 513 & 18.20 \\
\hline
\end{tabular}

Table 2 Distribution of Variable Frequency Category Item Implementing Patient Safety Sub (n = 99)

\begin{tabular}{llcc}
\hline Variables & & & \\
\hline Implementation of Patient Safety & Category & F & $\%$ \\
Sub variable teamwork & & & \\
Ask for help from the team needed & Good & 99 & 100 \\
& Less & 0 & 0 \\
Verbally asking for input team & Good & 66 & 66.7 \\
& Less & 33 & 33.3 \\
Receive Assertion and ideas & Good & 94 & 94.9 \\
& Less & 5 & 5.1 \\
Teams communicate effectively & Good & 93 & 93.9
\end{tabular}

Volume 8 Issue 1 April 2020 
Yayan Mulyana: Relationship between Healthcare Provider's Perception about Patient Safety and Patient Safety

\begin{tabular}{|c|c|c|c|}
\hline & Less & 6 & 6.1 \\
\hline \multirow[t]{2}{*}{ Teams work together to complete the task } & Good & 88 & 88.9 \\
\hline & Less & 11 & 11.1 \\
\hline \multirow[t]{2}{*}{ Tim act calmly and controlled } & Good & 92 & 92.9 \\
\hline & Less & 7 & 7.1 \\
\hline \multirow[t]{2}{*}{ Positive team morale } & Good & 88 & 88.9 \\
\hline & Less & 11 & 11.1 \\
\hline \multirow[t]{2}{*}{ Tim adapt to changing situations } & Good & 57 & 57.6 \\
\hline & Less & 42 & 42.4 \\
\hline \multirow[t]{2}{*}{ Monitor and review the situation } & Good & 58 & 58.6 \\
\hline & Less & 41 & 41.4 \\
\hline \multirow[t]{2}{*}{ The team anticipates the possibility of action } & Good & 56 & 56.6 \\
\hline & Less & 43 & 43.4 \\
\hline \multicolumn{4}{|l|}{ Sub communication variables } \\
\hline \multirow[t]{2}{*}{ The emergency department staff to communicate openly } & Good & 96 & 97 \\
\hline & Less & 3 & 3 \\
\hline \multirow[t]{2}{*}{ Specific structured communication (SBAR) } & Good & 86 & 86.9 \\
\hline & Less & 13 & 13.1 \\
\hline \multirow[t]{2}{*}{ Declare perception, action plan } & Good & 62 & 62.6 \\
\hline & Less & 37 & 37.4 \\
\hline \multirow[t]{2}{*}{ When communicating introduce myself } & Good & 57 & 57.6 \\
\hline & Less & 42 & 42.4 \\
\hline \multirow[t]{2}{*}{ Communication and respond to patients } & Good & 99 & 100 \\
\hline & Less & 0 & 0 \\
\hline \multirow[t]{2}{*}{ Komunikasi calm voice tone } & Good & 99 & 100 \\
\hline & Less & 0 & 0 \\
\hline
\end{tabular}

Table 3 Distribution of Implementing Patient Safety $(\mathbf{n}=99)$

\begin{tabular}{cccc}
\hline Variables & Category & F & \% \\
\hline Implementation of patient safety & Good & 50 & 50.5 \\
& Less & 49 & 49.5 \\
\hline
\end{tabular}

Table 4 Analysis of Perception Staff Relations IGD About Patient Safety and Implementation Patient Safety

\begin{tabular}{|c|c|c|c|c|c|c|c|}
\hline \multirow{2}{*}{\multicolumn{2}{|c|}{ Variable / Sub Variables }} & \multicolumn{4}{|c|}{ Implementation } & \multirow{3}{*}{$\mathbf{R}$} & \multirow{3}{*}{ P Value } \\
\hline & & \multicolumn{2}{|c|}{ Good } & \multicolumn{2}{|c|}{ Not Good } & & \\
\hline & & $\mathbf{f}$ & $\%$ & f & $\%$ & & \\
\hline \multirow[t]{2}{*}{ Teamwork } & Support & 37 & 67.3 & 18 & 32.7 & 0.375 & 0.000 \\
\hline & Does not support & 13 & 29.5 & 31 & 70.5 & & \\
\hline \multirow[t]{2}{*}{ Communication } & Support & 35 & 62.5 & 21 & 37.5 & 0.274 & 0.005 \\
\hline & Does not support & 15 & 34.9 & 28 & 65.1 & & \\
\hline
\end{tabular}


Yayan Mulyana: Relationship between Healthcare Provider's Perception about Patient Safety and Patient Safety

\begin{tabular}{llllllll}
$\begin{array}{l}\text { Patient safety } \\
\text { concept }\end{array}$ & Support & 33 & 63.5 & 19 & 36.5 & 0.273 & 0.005 \\
& & & & & & & \\
& & & & & & & \\
\multirow{2}{*}{ Perception } & Does not support & 17 & 36.2 & 30 & 63.8 & & 0.000 \\
& Support & 39 & 67.2 & 19 & 32.8 & 0.394 \\
\hline
\end{tabular}

Table 2 above indicates that the observation of the majority $(80 \%)$ of respondents either category on implementation of patient safety sub-variables teamwork and communication. Only a small proportion of respondents less category $(20 \%)$ on the implementation of patient safety sub-variables teamwork and communication in the ED (RSD) Cirebon.

Table 3 showed that less than half (49.5\%) category lacking implementation of patient safety, only half $(50.5 \%)$ categories, both in the implementation of patient safety in the ED (RSD) Cirebon.

Based on the results in Table 4, it shows the $p$-value $<0.05$, which means the existence of a positive correlation between the variables of the implementation of patient safety with teamwork variable ( $\mathrm{p}$-value $=0.000$ ), communications ( $\mathrm{p}$-value $=0.005)$, the concept of patient safety ( $\mathrm{p}$-value $=0.005)$, and perception $(\mathrm{p}$-value $=0.005)$.

\section{Discussion}

The analysis showed that no significant relationship between teamwork and implementation of patient safety with $p$ value $=0.000$. This is in line with several studies Manser (2009) revealed that teamwork can ensure patient safety in service in the emergency department. As well as research Kohn et al. (2000) stated that the multidisciplinary teamwork in the emergency services are essential in providing a safe service. Teamwork is defined as two or more individuals working together to achieve the goals that were set, has a special duty of competence and the role of specialized labor, use of shared resources, and communicate to coordinate and adapt to change (Brannick et al., 1997).

The results also showed that $48.5 \%$ of respondents do not support the ED staff perceptions of patient safety, $44.4 \%$ of them do not support the perception of sub-variable domain barriers team teamwork and mutual support. Review questionnaire is known that the ED staff did not support the statement item include, things are often not pleasant to cooperate with other staff from the emergency department, ask for help from team members is a sign that an individual does not know how to do his job effectively, provide assistance to the team members is a sign that an individual currently does not have activities to do. These results will impact on the implementation of patient safety. This is in line with research Pronovost et al. (2006) team collaboration among service providers that are not effective are the factors that contribute to unexpected events.

This current study also has pointed out, a significant relationship between communication and implementation of patient safety with $p$ value $=0.005$. This is in line with research Woloshynowych et al. (2007) in the emergency department of London stating that communication between health workers is an essential prerequisite for ensuring that the complex clinical environments run effectively and efficiently. These results indicate that the most important objective in the communication activities related to the emergency department patient management. The study also found a significant relationship between communication with patient safety.

Other studies Redley et al. (2017) in the emergency department the city of Victoria reveals that effective interprofessional communication is essential for a comprehensive clinical handover in the ER, where health professionals from different disciplines to work independently but has a complementary role in providing services to patients. Collaborating with other team members in the discussion of handover supported collective wisdom and responsibility for problem solving and decision making. Communication is important to provide information, ideas or feelings for work efficiency and work 
safety. It also provides knowledge, establish behavior patterns essential for leadership and teamwork in providing care for patients (WHO, 2009).

The results also showed a significant relationship between knowledge and patient safety in applying the concept of patient safety with a $\mathrm{p}$-value $=0.005$. Within the scope of the emergency department, health professionals must be able to manage patient safety risks by using their knowledge to maintain a safe level of patient care (Leape et al., 2009) This is in line with the results of Bawelle et al. (2013), that the level of knowledge of health professionals plays a role in support the implementation of patient safety. In addition, with increasing knowledge of health professionals about patient safety, clinical practice will be of high quality (Bagnasco et al., 2011).

The results also gained a significant relationship between the perception of the ED staff about patient safety and the implementation of patient safety with $p$-value $=0.005$. In line with the results of Aboshaiqah and Baker's (2013) research at Saudi Arabian hospitals which stated that, more than half of health care workers $(52 \%)$ showed support for the perception and implementation of patient safety. This was also supported by Robin, Stephen, and Judge (2007) who stated that, the perception of health workers about patient safety is the result of the interaction of individuals with environmental conditions influenced by the individual concerned, the purpose of perception and the situation. Other studies Agnew et al. (2013) state that climate patient safety the hospital is positively related to the behavior of the safety of health workers in health care.

Perception is integrated activity within the individual to provide an assessment of the views or opinions of an environmental condition (Sarwono, 2010). Perception is not just limited to the sensing in object or environment alone but the wider health personnel observe objects or environments that give the impression of him, so as to provide an assessment of the views or opinions. Individual perceptions can change, for example, from negative to positive or vice versa. According to Affonso et al. (2003) which states that the perception of health professionals on patient safety influential in the provision of health care, because health workers can ensure safety of services provided for patients.

\section{Conclusion}

The results of the study generally show that there is a relationship between the perception of ED staff about patient safety and the implementation of patient safety in ED (RSD) Cirebon.

ED staff support the perception of patient safety, but health workers are still found in the category of lack in the application of patient safety. It is hoped that this research can be input for those involved, especially the ED (RSD) Cirebon in the preparation of work programs and policies to support the improvement of perceptions about patient safety and the implementation of patient safety including training related to teamwork and communication, and developing clear guidelines for health workers. Patient safety education and training using simulation methods can provide an overview in the implementation of patient safety. So it must be a priority for health workers, in an effort to improve the application of patient safety in emergency departments.

\section{References}

Aboshaiqah, A., \& Baker, O. (2013). Assessment of nurses' perceptions of patient safety culture in a Saudi Arabia hospital. Journal of Nursing Care Quality. 28(3), 272-80. https://doi.org/10.1097/ ncq.0b013e $3182855 \mathrm{cde}$

Affonso, D.D., Jeffs, L., Doran, D., \& Ferguson-Pare, M. (2003), "Patient safety to frame and reconcile nursing issues", Nursing Leadership, 16(4), pp. 69-81. https://doi. org/10.12927/cjnl.2003.16232

Agency for Healthcare Research and Quality. (2013). About Team STEPPS. Retrieved July 16, from http://www.ahrq.gov/team stepp / about-teamstepps/index.html 
Agency for Healthcare Research and Quality. (2007). Guide to patient safety indicators Version 3.1. U.S. Department of Health and Human Services, Agency for Healthcare Research and Quality.

Agnew et al. (2013) Patient safety climate and worker safety behaviours in acute hospitals in Scotland. Journal of Safety Research, 45, 95-101. https://doi.org/10.1016/j. jsr.2013.01.008

Australian College for Emergency Medicine. (2014). Emergency Department Design Guidelines, G15. Third Section, Australian College for Emergency Medicine.

Bagnasco, A., Tibaldi, L., Chirone, P., Chiaranda, C., Panzone, M.S., Tangolo, D., \& Sasso L. (2011). Patient safety culture: An Italian experience. Journal of Clinical Nursing, 20, 1188-1195. https://doi. org/10.1111/j.1365-2702.2010.03377.x

Bawelle. (2013). Hubungan pengetahuan dan sikap perawat dengan pelaksanaan keselamatan pasien (patient safety) di Ruang Rawat Inap RSUD Liun Kandage Tahuna. ejournal keperawatan 1(1). https://doi. org/10.35790/jkp.v1i1.2237

Bovbjerg. R.R., Miller, R.H., \& Shapiro D. (2001). Paths to reducing medical injury: Professional liability and discipline vs. patient safety. J Law Med Ethics, 29, 369-380. https://doi.org/10.1111/j.1748-720x.2001. tb00354.x

Brannick et al. (1997). Series in applied psychology. Team performance assessment and measurement: Theory, methods, and applications. Lawrence Erlbaum Associates Publishers.

Brenna, M.F. (2016). Patient safety in the emergency department. Emergency Medicine.

Conner. (2005). The theory of planned behaviour and health behaviours. In M. Conner \& P. Norman (Eds.), Predicting Health Behaviour: Research and Practice with Social Cognition Models, 2nd Ed (pp.
170-222). Open University Press.

Cooperetal.(2010).Ratingmedicalemergency teamwork performance: development of the Team Emergency Assessment Measure (TEAM). Resuscitation; 81:446-52

Depkes RI. (2011). Standar Pelayanan Keperawatan Gawat Darurat di Rumah Sakit. (Standards for Emergency Nursing Services in Hospitals). Kementrian Kesehatan RI.

Emaliyawati, E., Prawesti, A., Yosep, I., \& Ibrahim, K. (2016). Manajemen Mitigasi Bencana dengan Teknologi Informasi di Kabupaten Ciamis. Jurnal Keperawatan Padjadjaran, 4(1). https://doi.org/10.24198/ jkp.v4i1.139

Guttmann. A., Schull, M.J., Vermeulen, M.J., \& Stukel, T.A. (2011). Association between waiting times and short term mortality and hospital admission after departure from emergency department: Population based cohort study from Ontario, Canada. $B M J$, 342. https://doi.org/10.1136/bmj.d2983

Horwitz, L.I., Meredith, T., Schuur, J.D., Shah, N.R., Kulkarni, R.G., \& Jenq, G.Y. (2009). Dropping the baton: A qualitative analysis of failures during the transition from emergency department to inpatient care. Ann Emerg Med., 53(6), 701-710. https://doi. org/10.1016/j.annemergmed.2008.05.007

Jeffs, L, Abramovich, I.A., Hayes, C., Smith, O., Tregunno, D., Chan, W.H., \& Reeves, S. (2013). Implementing an interprofessional patient safety learning initiative: Insights from participants, project leads and steering committee members. BMJ Qual Saf, 22, 923- 930. http://dx.doi.org/10.1136/ bmjqs-2012-001720

Kohn, L.T., Corrigan, J.M., \& Donaldson, M.S. (2000). To err is human: Building a safer health system. National Academy Press.

Leape, L., Berwick, D., Clancy, C., Conway, J., Gluck, P., Guest, J., Lawrence, D., Morath, J., O'Leary, D., O’Neill, P., Pinakiewicz, D., Isaac, T., \& Lucian Leape Institute at the National Patient Safety Foundation 
Yayan Mulyana: Relationship between Healthcare Provider's Perception about Patient Safety and Patient Safety

(2009). Transforming healthcare: a safety imperative. Quality \& safety in health care, 18(6), 424-428. https://doi.org/10.1136/ qshc.2009.036954

Lena, M., Berga, B., Ehrenbergc, A., Florinc, J., Jan, O., \& Katarina, E. (2012). An observational study of activities and multitasking performed by clinicians in two Swedish emergency departments. European Journal of Emergency Medicine, 19, 246-251. https://doi.org/10.1097/ mej.0b013e32834c314a

Manser, T. (2009). Teamwork and patient safety in dynamic domains of healthcare: A review of the literature. Acta Anaesthesiol Scand, 53, 143-151. https://doi.org/10.1111/ j.1399-6576.2008.01717.x

Ministry of Health. (2011) Patient safety indicator reporting: Ontario totals. Toronto, Retrieved September 2011, 2019, from http:// patientsafetyontario .net/ Reporting /en/ PSIR_ProvincialIndicatorReporting.aspx? Vi ew $=1 \&$ hosptid $=1444 \&$ seltype $=4 \&$ str $=\mathrm{S}$

Patel, V.L., \& Cohen, T. (2008). New perspectives on error in critical care. Current opinionincriticalcare, 14(4),456-459.https:// doi.org/10.1097/mcc.0b013e32830634ae

Peters \& Peters. (2008). Medical Error and Patient Safety: Human Factors in Medicine. CRC Press, Taylor \& Francis Group.

Pronovost et al. (2006). How will we know patients are safer? An organization-wide approach to measuring and improving safety, Critical Care Medicine, 34(7), 1988-1995 https://doi.org/10.1097/01. CCM.0000226412.12612.B6

Redley et al. (2017). Interprofessional communication supporting clinical handover in emergency departments: An observation study. Australasian Emergency Nursing Journal, 20(3), August 2017, Pages 122-130. https://doi.org/10.1016/j.aenj.2017.05.003

Robbins, P., Stephen, \& Judge, A.T. (2007). Organizational Behaviour. Prentice Hall.
Runciman, W., Hibbert, P., Thomson, R., Van Der Schaaf, T., Sherman, H., \& Lewalle, P. (2009). Towards an international classification for patient safety: Key concepts and terms. Int J Qual Perawatan Kesehatan, 21(1), 18-26. https://doi.org/10.1093/intqhe/ $\underline{\text { mzn057 }}$

Sarwono, S.W. (2010). Psikologi sosial: Psikologi kelompok dan psikologi terapan. (Social psychology: Group psychology and applied psychology). Balai Pustaka.

Shari, W. W., Suryani, S., \& Emaliyawati, E. (2014). Emotional Freedom Techniques dan Tingkat Kecemasan Pasien yang akan Menjalani Percutaneous Coronary Intervention. Jurnal Keperawatan Padjadjaran, 2(3). https://doi.org/10.24198/ jkp.v2i3.83

Sherman. H., Castro, G., Fletcher, M., Hatlie, M., Hibbert, P., Jakob, R., et al. (2009). Towards an International Classification for Patient Safety: The conceptual framework. Int J Qual Health Care, 21(1), 2-8. https:// doi.org/10.1093/intqhe/mzn054

Shojania, K.G., Duncan, B.W., McDonald, K.M., et al., eds. (2001). Making health care safer: A critical analysis of patient safety practices. Evidence Report/Technology Assessment, 43. Retrieved September 8, 2019, from https://www.ncbi.nlm.nih.gov/ books/NBK26966/

Sobur. (2011). Psikologi Umum. (General Psychology). CV Pustaka setia.

Sorra, J., Famolaro, T., Dyer, N., Nelson, D., \& Khanna, K. (2009). Hospital survey on patient safety culture: Comparative database report. Agency for Healthcare Research and Quality.

Walgito. (2002). Pengantar Psikologi Umum. (Introduction to General Psychology). Yogyakarta.Andi Offset

Westbrook, J.I. (2014). Interruptions and multi-tasking: Moving the research agenda in new directions. BMJ quality \& safety, 23(11), 877-9. https://doi.org/10.1136/ 
Yayan Mulyana: Relationship between Healthcare Provider's Perception about Patient Safety and Patient Safety

bmjqs-2014-003372

Woloshynowych, M., Davis, R., Brown, R., \& Vincent, C. (2007). Communication patterns in a UK emergency department. Annals of emergency medicine, 50(4), 407-13. https:// doi.org/10.1016/j.annemergmed.2007.08.001

World Health Organization. (2009). The conceptual framework for the international classification for patients a fe $t y$. Retrieved August 28, 2019, from http:// wwwwhoint/patientsafety/implementation/ taxonomy/ publications/en/.

World Health Organization [WHO]. (2009). Human factors in patient safety: Review of topics and tools. Report for Methods and Measures Working Group of WHO Patient Safety.

World Health Organization [WHO]. (2009). The conceptual framework for the International Classification for Patient Safety. Retrieved August 28, 2019, from http:// wwwwhoint/patientsafety/implementation/ 